\title{
JOURNAL.RU
}

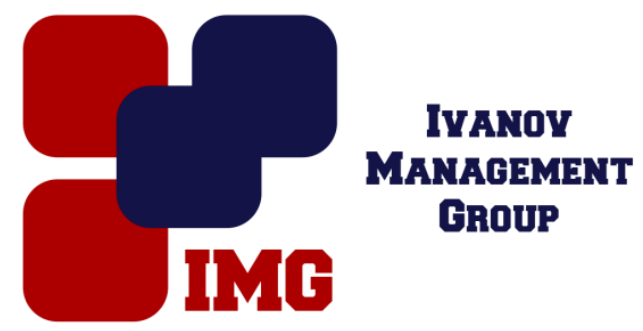

Улискина Т.К. МГТУ им. Н.Э. Баумана Москва, Россия

doi: $10.18411 / 1 \mathrm{j}-31-05-2017-36$

idsp 000001:1j-31-05-2017-36

\section{Использование в высшей школе интенсивных методов в обучении немецкому языку с нулевого уровня}

\begin{abstract}
Аннотация
Статья посвящена изучению использования в высшей школе интенсивных методов в обучении второму иностранному языку с нулевого уровня. Она обобщает результаты многолетней работы, направленной на совершенствование процесса обучения немецкому языку.

Ключевые слова: использование, память, метод,навыки, язык.

Обучение второму иностранному языку будущих бакалавров лингвистики по направлению подготовки 45.03.02 - «Лингвистика», по профилю подготовки «Перевод и переводоведение» представляет определённые трудности, обусловленные намеченными целями и задачами. Целью преподавания этой дисциплины является подготовка с нулевого уровнябакалавра лингвистики, способного решать профессиональные задачи в области устного и письменного перевода. Именно это стало для автора статьи отправной точкой в поисках резервных возможностей для «активизации процесса обучения» при соблюдении всех требований к качеству подготовки. Так для автора статьи обозначилась тема исследования - совершенствование процесса обучения второму иностранному(немецкому) языку с нулевого уровня черезизучение и использование в высшей школе интенсивных методов обучения, разработанных болгарским учёным Георгием Лозановым и его последователями в нашей стране Л.Ш. Гегечкори, И.А. Зимней, Г.А. Китайгородской, В.В. Петрусинским, И.Ю. Шехтером. Каждое направление, разработанное перечисленнымиисследователями
\end{abstract}


заслуживает особого внимания, тщательного изучения, апробации и описания.На этом основании автору статьи приходит идея - на основе уже разработанных направлений создать авторскую концепцию, представляющую собой синтез уже разработанных известными исследователями эффективных приёмов, включая и авторские приёмы.

\section{Л.Ш. Гегечкори - «цикловая и межцикловая система»}

Важность его разработки заключается в последовательном чередовании циклов устной речи (речевая подготовка) и межцикловых этапов обучения (языковая подготовка). По Л.Ш. Гегечкори, основная цель межциклового этапа дать соответствующую ориентировку в языке и помочь учащимся сознательно осмыслить те языковые явления, которые были ранее восприняты главным образом интуитивно в коммуникативных актах циклов устной речи.

И.А. Зимняя - «психологические особенности интенсивного обучения взрослых иностранному языку»

Большое внимание психологическим особенностям интенсивного обучения уделяет И.А. Зимняя: а) «мнемическим особенностям» обучаемых;

б) «коммуникативной связанности», позволяющей обеспечить обучаемым овладение ими информацией в больших объёмах, создавая одновременно ощущение лёгкости в восприятии тектов-полилогов, избавляя учебный процесс от монотонности и одновременно поддерживая мотивацию при отработке лексикограмматическиго материала; в) «концентрированности в организации учебного материала», а именно в учебных текстах-полилогах, что в свою очередь предопределяет «концентрированность организации учебного процесса» в целом.

Г.А. Китайгородская - «метод активизации личности и коллектива»

«Практика доказала богатые возможности,заложенные в системе суггестопедическогообучения», -такую оценку даёт Г.А. Китайгородская изучаемому автором статьи направлению[1, 30].В рамках интенсивного метода обучения иностранным языкамГ.А. Китайгородскаяразработала своё авторское направление - «активизация личности и коллектива», позволившее автору статьи разработать важные положения, способствующие успешному обучению иностранному языку: а) повышение мотивации обучаемых; б) снятие психологических барьеров; в) поддержание чувства уверенности обучаемых; г) установление комфортного доброжелательного микроклимата в учебном коллективе.

Г. Лозанов - «суггестопедический интенсивный метод обучения иностранным языкам» 
Георгий Лозанов разработалметод обучения иностранному языку, основанный на внушении, и тем самым предложил совершенно иной подход к обучению иностранным языкам.«Суггестивные виды деятельности расходуют минимальную энергию. Одно из псевдопарадоксальных явлений в суггестопедии это сверхзапоминание без какой бы то ни было усталости, даже при ясно выделяющемся эффекте отдыха», - так обосновывает Георгий Лозанов преимущества своего метода [2, 63].

В.В. Петрусинский - «суггестокибернетический интегральный метод»

Важную роль в обучении, по мнению В.В. Петрусинского, играет предъявление объёмного учебного материала для «целостного запоминания», что позволяет автоматизировать на начальном этапе почти все основные виды деятельности в обучении иностранным языкам, преследующие цель - обеспечить запоминание обучающимися объёмного лексического запаса и грамматических конструкций, которые в дальнейшем обучении будут служить опорой в «речепорождении».

И.Ю. Шехтер - «эмоционально-смысловой метод»

И.Ю. Шехтер предлагает в качестве основы «эмоционально-смыслового метода» идею «смыслообразования», возникающего у обучаемых в условиях ролевой игры, поскольку, его словами, «цель коммуникации - обмен смыслами, а не значениями языковых единиц», то единственную возможность в овладении речевым общением он находит в опоре на «смыслообразование», возникающее в условиях ролевой игры, и на «эмоциональное соучастие обучаемого».

В поисках способов достижения намеченной цели обращение автором статьи к методам интенсивного обучения не является случайным. Прежде всего, это обращение было продиктовано заложенным в них непременным условием обучение языковому общению. Основывая свой анализ на многолетних наблюдениях, автор данного исследования приходит к выводу- эффективным способом обучения иностранному языку является обучение через коммуникативные тематические блоки и модели, так как они позволяют обучающимся максимально приблизиться в процессе обучения к естественным коммуникативным ситуациям. Это означает, что при предъявлении новой коммуникативной темы общения, состоящей из коммуникативных блоков и моделей, тематического лексикона и грамматических конструкций, преследуется цель - обеспечить обучаемым возможность овладения лексическим и грамматическим материалом через коммуникативное общение с использованием языковых средств -готовых коммуникативных конструкций по теме общения, 
которые являются основой сначала для их интерпретации, а затем и для выражения мыслей по предлагаемой коммуникативной ситуации.

Особую роль в обучении иностранным языкам играют аудио- и визуальные опоры в первую очередь в создании коммуникативных моделей общения, максимально приближенных к естественным коммуникативным ситуациям. Кроме того, аудио- и визуальная опоры способствуют ознакомлению обучаемых с культурой, обычаями, традициями, психологией носителей языка.

На практике исследовательуделяет особое внимание работе с коммуникативнымитематическимиблокамии моделями общения. В качестве примера предлагается коммуникативная тематическая ситуация - опоздание.

Коммуникативный тематическй блок общения -

Dieverspaetung

hereinkommen/reinkommen

Darf ich herein/rein?

um Entschuldigung/Verzeihung bitten

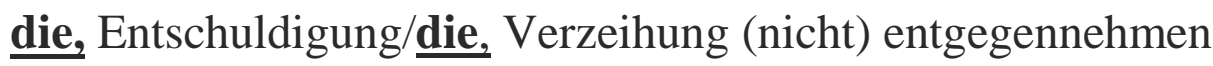

Deine Verspaetung ist die groesste Bescherung fuer mich.

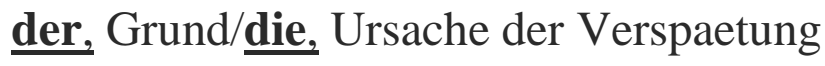

zu Hause/im Studentenheim

verschlafen/sich verzoegern

das, Hotel «Mama»/im Hotel «Mama» wohnen

das, Studentenheim/im Studentenheim wohnen

nebenan/daneben wohnen

ziemlich weit von der Universitaet wohnen

der, Wecker/den Wecker aufziehen/abstellen

der, Vorortszug/den Vorortszug verpassen

die, Uhr/die, Zeit/die, Stunde

Um wieviel Uhr musst du los?

Wieviel Zeit dauert deine Fahrt?

Die Fahrt dauert anderthalb/eineinhalb Stunden.

die, Strassenbahn nehmen/mit der Strassenbahn fahren

der, Bus/den Bus nehmen/mit dem Bus fahren

die, S-Bahn/Stadt-Bahn/mit der S-Bahn fahren

der, Anspruch/in Anspruch nehmen

Wieviel Zeit nimmt deine Fahrt in Anspruch?

Es ist mir peinlich! 
rechtzeitig losgehen/losfahren/puenktlich zum Unterricht kommen

Mach(e) es wieder gut

der, Platz/den Platz nehmen!

Коммуникативные тематические модели общения

A)- Guten Morgen, Frau Uliskina!

- Guten Morgen, Uljana!

- Darf ich hereinkommen?

- Ja, du darfst hereinkommen!

- Ich bitte um Entschuldigung fuer meine Verspaetung!

- Wo wohnst du? Wohnst du im Hotel «Mama» oder im Studentenheim?

- Ich wohne im Studentenheim.

- Deine Verspaetung ist eine grosse Bescherung fuer mich!

Das Studentenheim liegt doch nebenan! Was ist los?

Du kommst ja zum Unterricht zu Fuss!

Ja, das stimmt! Es ist mir sehr peinlich, aber ich habe mich im Studentenheim verzoegert.

Darf ich meinen Platz nehmen?

Ja, du darfst deinen Platz nehmen! Aber ich kann deine

Entschuldigung nicht entgegennehmen!

Du musst rechtzeitig losgehen und puenktlich zum Unterricht kommen!

Mach(e) es wieder gut bitte!

Ich danke Ihnen, Frau Dozentin!

Ich mach(e) es wieder gut!

B) - Guten Morgen, Frau Uliskina!

- Guten Morgen, Nika!

- arf ich rein?

Ich bitte um Verzeihung fuer meine Verspaetung!

- Ja, komm(e) bitte herein! Was ist los?

- Du bist zu spaet gekommen!

- Wo wohnst du? Wohnst du im Hotel Mama?

- Das stimmt! Ich wohne im Hotel «Mama».

- Liegt es ziemlich weit von der Universitaet?

- Ja, Sie haben recht!

- Wieviel Zeit nimmt deine Fahrt zur Universitaet in Anspruch? 
- Eineinhalb/anderthalb Stunden!

- Ich fahre zum Unterricht mit der Stadt-Bahn.

- Heute habe ich noch dazu meinen Vorortszug verpasst!

- Schade! Aber das ist ja kein Entschuldigungsgrund!

- Es tut mir leid! Ich mach(e) es wieder gut!

- Nimm bitte Platz!

- Danke Ihnen!

C) - Guten Morgen, Frau Dozentin! Darf ich reinkommen?

- Ja, du darfst herein! Was ist los? Du bist immer puenktlich!

- Wohnst du doch nebean!

- Sie haben recht! Ich wohne daneben! Ich habe verschlafen!

- Hast du den Wecker gestern nicht aufgezogen?

- Doch! Ich habe den heute abgestellt und ich

- bin wieder eingeschlafen.

- Verzeihen Sie es mir bitte! Ich mach(e) es wieder gut!

- Ich kann es dir verzeihen. Aber es gibt eine grosse Frage,

- ob dein Arbeitgeber es dir verzeiht!

- Nimm bitte Platz! Mach(e) es wieder gut bitte!

- Dankeschoen!

После ознакомления с предложенным лексическим и грамматическим материалом, используемым в коммуникативных тематических моделях общения, обучаемым предлагаются для просмотра и прослушивания тексты или полилоги по изучаемой коммуникативной теме. Послепросмотра или прослушивания нового учебного материала обучаемые сразу переходят к его закреплению с использованием визуальной опоры по предлагаемой авторской методике, по которой обучаемые получают задание: прочестьза преподавателемпо установленной заранее цепочкекаждое предложение введённого ранее текста или полилога. Следует особо отметить эффективность этого приёма, гарантирующего полное запоминание нового учебного материала. Завершением проработки нового учебного материала является общение участников группы по новой коммуникативной тематической модели общения. Участникам общения предлагается использовать такие приёмы, как вовлечь других участников группы в общение, ответить на вопрос и задать встречный вопрос, переадресовать вопрос другому участнику общения. Это один из авторских приёмов, которые Г. А. Китайгородская называет определяющими в концепции интенсивного обучения. 
Для обозначения подобных приёмов она вводит понятие - «активизация обучения», её словами,- это «процесс, направленный на достижение состояния активности личности и сохранения этого состояния» [1,10]. Под этим она понимает «активизацию деятельности преподавателя и учащегося, преподавателя и учебной группы», исходя из того факта, «что активное общение и взаимодействие преподавателя с группой вызывает активность учащихся в общении и взаимодействии не только с преподавателем, но и друг с другом» $[1,10]$. Завершением работы над новой коммуникативной темой являются ролевые игры, которым исследователи изучаемых методов, систем и направлений в интенсивном обучении уделяют особое внимание.

Намеченная автором исследования цель - совершенствование процесса обучения в высшей школе второму иностранному (немецкому) языку с нулевого уровня - достигается через изучение и использование уже имеющихся эффективных приёмов, средств и способов, совокупность которых позволяет автору статьи сформулировать авторскую концепцию «суггестивного воздействия на резервные объёмы памяти обучаемых с опережением устной речи и использованием аудиовизуальных технических средств» [3, 50]. Исходя из того, что именно непрерывные поиски резервных возможностей «активизации учебного процесса» в обучении иностранному языку являютсянепременным условием совершенствованиясистемы обучения иностранным языкам в целом, автор статьи считает данную исследовательскую работу целесообразной.

\section{$* * *$}

1. Китайгородская Г.А., Интенсивное обучение иностранным языкам - теория и практика. М.:«Русский язык», 1992, с. 10, 30.

2. Лозанов Г., Основы суггестологии // Материалы III Международного симпозиума по проблемам суггестологии.София: 1973, с. 63.

3. Uliskina T.K., Suggestive impact on reserve memory of learners in the foreign language acquisition based on speaking skills precedence and use of audio - visual aids // «Modern science»,M.: 2017. - № 01. - p. 50. 